\title{
MATRIMONIO Y HOMOSEXUALIDAD
}

NIEVES MONTESINOS SÁNCHEZ

Universidad de Alicante

\begin{abstract}
«Nacisteis juntos, y juntos permaneceréis para siempre [...]. Y manteneos unidos pero no demasiado unidos: porque las columnas del templo se encuentran separadas. Y ni el roble crece bajo la sombra del ciprés ni el ciprés bajo la del roble»*
\end{abstract}

El Congreso de los Diputados aprobó el 21 de abril de 2005, con 183 votos a favor, 136 en contra, y 3 abstenciones la reforma del Código Civil que permite el matrimonio entre personas del mismo sexo ${ }^{1}$. Posteriormente al pasar la reforma al Senado, tal y como es preceptivo, éste vetó el proyecto, merced a una propuesta que presentaron el Partido Popular, y Unió Democrática de Catalunya. La propuesta fue aprobada, lo que supuso la vuelta de la reforma al Congreso. Aprobándose finalmente el 30 de junio de $2005^{2}$, la Ley se publicó en el Boletín Oficial del Estado el día 2 de julio, y entró en vigor al día siguiente.

Con ella, España entra a formar parte de los pocos países en los que se admite el matrimonio entre personas del mismo $\mathrm{sexo}^{3}$, con una nueva redacción del artículo 44 Código Civil donde se establece: «1. El hombre y la mujer tienen derecho a contraer matrimonio conforme a las disposiciones de este Código. 2. El matrimonio tendrá los mismos requisitos y efectos cuando ambos contrayentes sean del mismo o de diferente sexo" ${ }^{4}$.

* Gibrán Kalhil Gibrán, El Profeta, ("El matrimonio»).

1. El 18 de junio, bajo el lema «la familia sí importa», se convocó en Madrid por El Foro Español de la Familia una manifestación a la que acudieron multitud de personas contra la proyectada Ley. La manifestación, de la que se hicieron eco todos los medios de comunicación, contó con el apoyo de la Iglesia Católica española y del Partido Popular.

2. Contó con 187 votos a favor: PSOE, ERC, Izquierda Unida, PNV, BNG, CC, CHA, dos diputados de CIU y una diputada del PP; 147 en contra: PP y Uniò; y cuatro abstenciones.

3. Con reconocimiento nacional en Países Bajos (2001), Bélgica (2003) y Canadá (2005).

4. Ap. 2 introducido por la L. 13/2005 de 1 de julio, art. uno (BOE de 2 de julio).

Feminismo/s, 8, diciembre 2006, pp. 159-180 
Tal modificación estaba ya prevista en el programa electoral del PSOE en las últimas elecciones generales ${ }^{5}$. A partir de aquí se desencadena una nueva problemática y polémica a la que haré referencia más adelante, y de la que dan cuenta, en mayor o menor medida los diferentes estudios de reciente publicación.

\section{ANTECEDENTES: LA REGULACIÓN DE LAS UNIONES DE HECHO}

El matrimonio entre personas del mismo sexo ha sido el resultado final de un largo recorrido, que se inicia con la problemática y posible regulación, a raíz, entre otras, de las diferentes demandas sociales y jurídicas, de las uniones de hecho (UDH).

Sobre él he tenido ocasión de trabajar en otros momentos ${ }^{6}$, razón por la cual considero interesante, partiendo de la premisa inicial de que el tema en su conjunto debe enmarcarse en el Estado social y democrático de Derecho que dibuja y define nuestro texto constitucional, y atendiendo a la normativa internacional y europea, poner sobre el tapete cuál ha sido la postura que comparto, para poder conocer el estado de la cuestión.

Si son al menos dos las instituciones que se podían sentir afectadas en el tema de la regulación de las UDH y que comprometen directamente las relaciones entre Derecho y Género: el matrimonio y la familia, la cuestión sería ir más allá del matrimonio. Y manteniendo la supervivencia de la construcción jurídica matrimonial y el derecho personal de acogerse o no a ella, debiera abandonase la concepción tradicional. Se trataría pues, de realizar una configuración de la familia y por ende del derecho de familia desde la institución susceptible de protección.

Ello supondría en consecuencia la no juridificación o formalización de las $\mathrm{UDH}$, excepción hecha de las uniones homosexuales, dependiendo de que se considere o no oportuno su acceso al matrimonio; y las limitaciones serían fru-

5. La propuesta presentada por el PSOE, que contaba con el visto bueno de la Federación Estatal de Lesbianas, Gays y Transexuales (FELGT), suponía el cambio de tres artículos del Código Civil: art. 44: «El hombre y la mujer tienen derecho a contraer matrimonio conforme a las disposiciones de este Código». Se cambia el sujeto por 'cualquier persona'. Art. 66: «El marido y la mujer son iguales en derechos y deberes». Se cambia el sujeto por 'los cónyuges'. Art. 67: «El marido y la mujer deben respetarse y ayudarse mutuamente y actuar en interés de la familia». Se hace lo mismo que en el art. 66. Estas propuestas permiten también la adopción por ambos cónyuges. Puede verse: El País (Sociedad), de 25 de marzo de 2004.

6. Pueden verse mis estudios: «Familia y Derecho: aproximación a la configuración jurídica y social del modelo familiar», en Martinell, J. $\mathrm{M}^{a}$ y Areces, $\mathrm{M}^{\mathrm{a}} \mathrm{T}$. (eds.): Uniones de hecho, Lleida, Universitat de Lleida, 1998, pp. 359-368; «La iniciativa legislativa y las uniones de hecho", en Estudios Jurídicos en homenaje al profesor Vidal Guitarte, Valencia, Serv. Pub. Diputación de Castellón, 1999, pp. 653-663; «La conflictividad jurídica de las uniones homosexuales», en Santos Díez, J. L. (ed.): XVIII Jornadas de la Asociación Española de Canonistas, Salamanca, Universidad Pontificia de Salamanca, 1999, pp. 353-369; «Demandas sociales y respuestas jurídicas a propósito de las uniones de hecho», en Castán Vázquez, J. Mª , Guzmán Pérez, C., Pérez-Agua López, T. y Sánchez García, J. Ma. (coords.): Hominum causa omne ius constitutum est. Escritos sobre el matrimonio en homenaje al Prof. José Ma Díaz Moreno, Madrid, Universidad Pontificia Comillas, 2000, pp. 1433-1458. 
to de una decisión de política legislativa acorde con los principios y derechos constitucionales. Pero no cabría esconder la regulación de las uniones homosexuales en la globalidad de las UDH, ya que no responden a unas mismas necesidades.

Entre las razones por las que se defiende esta vía de solución, cabe destacar que tiene perfectamente cabida dentro de un Estado social y democrático de Derecho, personalista como el nuestro y a mayor abundamiento desde la perspectiva que ofrece el artículo 39 del texto constitucional ${ }^{7}$. Además, se está hablando de la familia proteiforme, pero no sería conveniente la clasificación de modelos familiares o la juridificación de familias de distinta categoría ya que podría ser atentatorio de los principios que recoge nuestro propio sistema. En este contexto la asimilación al modelo matrimonial podría estar fuera de lugar para personas que pueden voluntariamente adherirse o no al mismo, excepción hecha de aquellos efectos que se unen al matrimonio pero que no corresponden necesariamente al mismo por su naturaleza ${ }^{8}$.

Desde el conocimiento del marco jurídico de formación de la institución matrimonial y de la familiar, es necesario que la construcción estatal, civil, se realice por tanto no ignorando, pero sí al margen de componentes y connotaciones morales y religiosas, y teniendo presente y sobre la base de las repercusiones jurídicas que llevan consigo los procesos de transformación social. Es por ello que en un Estado de Derecho que proclama entre los principios rectores de la política social y económica la protección a la familia, habrá que estar atentos a la realidad social que nos sirve de referencia puesto que tiene una construcción jurídica. Es decir, es básica la interrelación con la construcción jurídica matrimonial y por ende con la familiar en el análisis de la problemática de las UDH, y del acceso, o no, al matrimonio de personas del mismo sexo. Pero, al mismo tiempo, hay que destacar que no siempre cuando se habla de UDH se incluyen tanto las heterosexuales como las homosexuales. Sobre todo porque la referencia generalizada es a las uniones extramatrimoniales. Quizá ello ha llevado a que a la hora de plantear una propuesta legislativa, se incluyan ambas de manera indistinta. Lo cual puede inducir a error a la hora de dar una respuesta clara a los conflictos que se plantean en uno u otro caso, ya que aunque en ocasiones puedan ser coincidentes, no son siempre necesariamente idénticos.

Ahora bien, analizar el debate producido requiere pasar revista a una serie de cuestiones básicas que han colaborado a la conformación y configuración de lo que ha sido y es el eje del debate jurídico, político y social. Obviamente desde esta aportación no pueden ser todas ellas analizadas, pero sí enunciadas con un mayor o menor desarrollo.

7. En particular conviene recordar el punto $1 \mathrm{del}$ art. 39: «Los poderes públicos aseguran la protección social, económica y jurídica de la familia».

8. Puede verse: VAlPUESTA FernándeZ, $M^{a}$ R.: «La institucionalización jurídica de la pareja. Registro de parejas de hecho", en Las Uniones de Hecho, Cádiz, Servicio de Publicaciones de la Universidad de Cádiz y Departamento de la Mujer del Excmo. Ayuntamiento de Jerez de la Frontera, 1995, pp. 47-66. 
Es sabido que las investigaciones sobre las UDH en España son relativamente recientes en el tiempo, aunque son conocidos estudios históricos sobre distintas situaciones familiares. A partir de aquí un primer punto de atención lo constituye el análisis tanto de la evolución doctrinal como jurisprudencial y legislativa en la materia ${ }^{10}$.

En un segundo punto habría que tener en cuenta la Constitución, el Tribunal Constitucional y las resoluciones europeas. En la Constitución especialmente los artículos 10, 14, 18 y 3911. Por lo que se refiere al Tribunal Constitucional aunque son numerosas y variadas sus resoluciones y no todas están en la misma línea, considero interesante resaltar que para el más alto Tribunal «Nuestra constitución no ha identificado la familia que manda proteger con la que tiene su origen en el matrimonio, conclusión que se impone no sólo por la regulación bien diferenciada de una institución y otra (artículos 32 y 39), sino también, junto a ello, por el mismo sentido amparador o tuitivo con el que la norma fundamental considera siempre a la familia, y en especial en el repetido art. 39, protección que responde a imperativos ligados al carácter 'social' de nuestro Estado (artículos 1,1 y 9,2) y a la atención, por consiguiente, de la realidad efectiva de los modos de convivencia» ${ }^{12}$, y aunque reiteradamente expresa que el matrimonio y la convivencia matrimonial no son realidades equivalentes, recuerda que «la Constitución no sólo protege a la familia que se constituye mediante el matrimonio -aunque a ésta la proteja especialmente- sino también a la familia como realidad social, entendida por tal la que se constituye voluntariamente mediante la unión de hecho, afectiva y estable de una pareja» ${ }^{13}$. En cuanto a las parejas homosexuales, no es una institución regulada jurídicamente, y no existe-como ocurre con el matrimonio al que se refiere el artículo 32- derecho

9. Especial atención merece la institución de la barraganía, véase: FOSAR BENLLOCH, E.: «Las uniones no matrimoniales en el derecho histórico español. La sucesión mortis causa a favor de los hijos extramatrimoniales en el derecho Civil aragonés", Revista Crítica de Derecho Inmobiliario, 59 (1983), pp. 133-176.

10. En la doctrina tanto civilistas como canonistas se han ocupado del tema, y éste ha sido objeto de discusión tanto en foros nacionales como europeos. Entre los civilistas, mención especial merece por ser de los primeros, el estudio monográfico de ESTRADA ALONSO, E.: Las uniones extramatrimoniales en el Derecho Civil español, Madrid, Civitas, 1986; entre los canonistas y por la importancia de la construcción del modelo matrimonial, NAVARRO VALLS, R.: Matrimonio y Derecho, Madrid, Tecnos, 1995; también, REINA, V. y MARTINELL, J.: Las uniones matrimoniales de hecho, Madrid, Marcial Pons, 1996. En la jurisprudencia, diferentes pronunciamientos se han decantado por la imposibilidad de la aplicación analógica de la normativa matrimonial a las UDH, entre ellos: SsTS de 18-5-82, 21-10-92, 22-7-93, 27-5-94. Y por lo que respecta a la legislación bastaría recordar aquellas normas en las que se ha ido produciendo una asimilación de efectos entre las uniones matrimoniales y las UDH: Ley de Arrendamientos urbanos, Código penal, etc.

11. Sobre la oportunidad de tomar en consideración el artículo 18 del texto constitucional, y la escasa atención que se le ha prestado al mismo en conexión con la Jurisprudencia europea y el CEDH, véase: MONTESINOS SÁNCHEZ, N.: «Familia y Derecho: aproximación...», op.cit., p. 364.

12. Véase STC 222/1992.

13. Véase STC $47 / 93$. 
constitucional a su establecimiento ${ }^{14}$. Y por último, no se pueden dejar de lado ni las diferentes resoluciones europeas en materia de no discriminación: Resolución del Consejo de Europa de 1 de octubre de 1981, Resolución del Parlamento Europeo de 13 de marzo de 1984, Resolución del Parlamento Europeo de 8 de febrero de 1994, ni la Jurisprudencia TEDH.

El tercer bloque para fijar el estado de la cuestión lo integran las proposiciones de los grupos parlamentarios. De ellas se sigue que la decisión de nuestros legisladores fue inicialmente -porque en la actualidad parece que esté todo aparcado- la del establecimiento de una normativa general que contemple a las UDH, y, partiendo de una definición de lo que se considera unión de hecho o contrato de unión civil, extender la aplicación normativa tanto a las uniones heterosexuales como a las homosexuales sin diferenciación entre ambas.

Si bien se presentaron diferentes proposiciones y proyectos, la toma en consideración inicialmente de la proposición de Coalición Canaria permitía utilizarla como instrumento base para el análisis de las posturas mantenidas por los grupos políticos. Todos parecían defender la regulación legislativa de las $\mathrm{UDH}$, sin ser coincidentes las modificaciones legislativas propuestas $\mathrm{y}$, desde una línea argumental y con justificaciones no siempre idénticas.

Para Coalición Canaria la necesidad de la regulación se apoya en el hecho de que "la aceptación social de las uniones de hecho libres es creciente en nuestra sociedad», y de que "no debe permanecer al margen del derecho positivo aquella convivencia de pareja estable e independientemente, o no, de la sexualidad de quienes la constituyan", con lo cual el legislador debe "eliminar las discriminaciones que afectan a estas uniones y a sus miembros, adoptando al tiempo medidas de protección efectivas». Siendo su finalidad la de "conectar los efectos de la unión matrimonial a las parejas estables de hecho mediante la elaboración de una ley modificativa sobre los preceptos afectados» en diferentes leyes ${ }^{15}$. Tan sólo el Grupo Parlamentario Federal de Izquierda Unida-Iniciativa per Catalunya introduce alguna innovación en su argumentación, ya que en vez de partir de la asimilación de determinados beneficios de la unión matrimonial a la UDH,

14. Véanse: SsTC 184/90 y 66/94. La admisión o no del matrimonio para los homosexuales genera una viva polémica cuya discusión se centra a nivel normativo en la necesidad de reforma del artículo 32 de la Constitución, o simplemente de los artículos 44, 66 y 67 del Código civil. Véase: IBARRA ROBLES, J.L.: «El reconocimiento de efectos jurídicos a las uniones de hecho en el ordenamiento español: su evolución y aspectos a considerar en la actual iniciativa legislativa", El Derecho Europeo ante la Pareja de Hecho, Barcelona, Cedecs Derecho, 1996, pp. 31-40.

15. Véase la Exposición de Motivos que antecede a la proposición, altamente ilustrativa y necesaria por imperativo del artículo 124 del reglamento del Congreso de los Diputados (Boletín Oficial de las Cortes Generales. Congreso de los Diputados. VI Legislatura, Serie B, n 90, p. 2). Por lo que se refiere al Partido Socialista, éste había partido de pronunciamientos muy similares, por ello la regulación debía ir encaminada a «identificar en las diferentes legislaciones sectoriales los supuestos en que serían extensivos los efectos de las uniones matrimoniales a las de hecho y elaborar una ley 'modificativa' que de nueva redacción a los correspondientes preceptos de aquellas al tiempo que establezca los requisitos que han de cumplir las uniones de hecho y la forma de acreditar los mismos» (Boletin Oficial de las Cortes Generales. Congreso de los Diputados. VI Legislatura, Serie B, n 87, pp. 1-2). 
su razonamiento gira en torno a la interpretación y aplicación del artículo 39 del texto constitucional, entendiendo que en él «no existe una referencia a un modelo de familia predeterminado ni predominante, lo que hace necesario una interpretación amplia de lo que debe entenderse por familia, consecuente con la realidad social actual y con el resto del articulado constitucional referido a la persona» ${ }^{16}$. Por su parte, en la última proposición que planteó el PP el objetivo era que "quienes lo deseen puedan formalizar una unión civil por medio de un contrato para garantizar la certeza exigida por el principio de seguridad jurídica, sin menoscabo del derecho fundamental a la intimidad ${ }^{17}$. Con ello se entiende que se respetan y amparan tanto las situaciones de quienes quieren formalizar una unión civil, como la de aquellos que quieren relacionarse más allá del Derecho.

Existe una diferencia básica entre ambas proposiciones ya que el grupo popular no habla ni de UDH, ni de familia; diferencia que se convierte en evidencia con la simple lectura de las definiciones o requisitos que se proponen en consonancia con la decisión de formalizar estas uniones.

La definición que en cada caso se plantea encierra su trascendencia, Coalición Canaria entiende que son parejas de hecho estables "las uniones de los mayores de edad o menores emancipados, sin vínculos de parentesco en primer o segundos grados de consanguinidad, que convivan en pareja con independencia de su sexualidad, al menos durante un año, libre, pública y notoriamente» ${ }^{18}$. El Grupo Popular introdujo una figura alternativa, el contrato de unión civil, que considera como tal aquel por el cual «dos personas físicas mayores de edad acuerdan convivir y prestarse ayuda mutua»19.

Casi todos los grupos habían manifestado ya su postura en momentos anteriores, e incluso algunos esperaban el dictamen o el proyecto que pudiera salir de la subcomisión encargada de estudiar el tema ${ }^{20}$. El dictamen de dicha subcomisión que retrasa, para unos sí y para otros no, la tramitación de la ley y que

16. Véase: Exposición de Motivos de la Proposición del Grupo Parlamentario Federal de Izquierda Unida-Iniciativa per Catalunya (Boletín Oficial de las Cortes Generales. Congreso de los Diputados, VI Legislatura, Serie B, $n^{\circ} 88$, pp. 1-2).

17. Véase: Exposición de Motivos de la Proposición de Ley Orgánica presentada por el Grupo Parlamentario Popular en el Congreso (Boletín Oficial de las Cortes Generales. Congreso de los Diputados, VI Legislatura, Serie B, n 117, pp. 1-2).

18. Véase artículo 1. En la proposición del PSOE, el tiempo requerido de convivencia era de dos años (art. 1). Y en la de Izquierda Unida, que era aproximadamente idéntica, se partía de una declaración de principios en su art. 1 del siguiente tenor: «Nadie puede ser discriminado por razón del grupo familiar del que forme parte, tenga éste su origen en la filiación, en el matrimonio o en la unión de dos personas que convivan por análoga relación de afectividad, con independencia de su orientación sexual. Se entiende nula, y sin efecto, cualquier norma legal o convencional que vulnere o contradiga este principio».

19. Véase art. 1 puntos 1,2 y 3. Debe llamarse la atención sobre el hecho de la imposibilidad de que sean parte del mismo los menores emancipados, a los que sí se referían las otras proposiciones.

20. Remito a las opiniones mantenidas por los diferentes grupos con ocasión de la toma en consideración de las proposiciones de ley del Grupo Socialista del Congreso, del Grupo Parlamentario Federal de Izquierda Unida-Iniciativa per Catalunya y del Grupo Parlamentario de Coalición 
incluye las conclusiones separadas de cada grupo parlamentario fue aprobado por unanimidad de todos los grupos. No obstante, el debate se reabrió entre los diferentes grupos con ocasión de la toma en consideración de la Proposición del Partido Popular ${ }^{21}$.

En relación con la problemática homosexual -parejas homosexuales a las que en absoluto se alude en la proposición, pero a las que tampoco se excluye ya que tienen cabida en el tenor literal del precepto anteriormente trascrito-, los populares se formulan una serie de interrogantes: «iEs posible con arreglo a nuestro ordenamiento constitucional la regulación del denominado matrimonio homosexual? ¿Es posible, en cualquier caso, la regulación de una unión homosexual similar a la del matrimonio, pero que no se llame matrimonio y que sea, en cambio, considerada como una unión familiar? Por último, la no equiparación de las parejas homosexuales a la situación matrimonial o familiar de heterosexuales, aunque sí se equiparen sus efectos ¿supone acaso una discriminación?». Y la respuesta que encuentran es «no es posible». No es posible con arreglo a nuestras leyes esa regulación o esa equiparación de situaciones, aunque sí lo sería equiparar los efectos, tomando también en consideración las decisiones del Tribunal Constitucional. Entienden, en consecuencia, que «no puede hablarse de discriminación si hablamos con objetividad de la realidad jurídica española». Es más, para los populares -pese a manifestar la legitimidad de la petición, el respeto y apoyo a las parejas homosexuales- nuestra Constitución no admite una reforma legislativa "encaminada a un pleno reconocimiento como si sus uniones fuesen un matrimonio o una unidad familiar", ya que para ello tendría que haberse propuesto la reforma de la Constitución. Y porque la concepción de la familia que emana de la Constitución es el «modelo de unión entre un hombre y una mujer y de los hijos que con ellos convivan. Con arreglo a su texto no solamente son posibles familias matrimoniales, sino también las no matrimoniales heterosexuales. Por ello la Constitución española se refiere a la protección de los hijos, cualquiera que sea su filiación, y a la protección a las madres, cualquiera que sea su estado civil ${ }^{22}$. Estas son algunas de las razones que justifican una ley que está en la frontera de lo posible, a pesar de no satisfacer a determinados grupos ${ }^{23}$.

Los restantes grupos parlamentarios, mayoritariamente contrarios a la proposición, también argumentan de modo muy directo sus posiciones. El Bloque Nacionalista Galego se opone por una serie de criterios que considera básicos:

Canaria, Diario de Sesiones. Congreso, n 86 de 27 de mayo. Además a las posturas mantenidas por los grupos parlamentarios ya hice referencia en MONTESINOS SÁNCHEZ, N.: «La iniciativa legislativa y las uniones de hecho", op.cit., passim.

21. Véase: Diario de Sesiones. Congreso, n 120 , de 25 de noviembre de 1997.

22. Para el discurso del señor Trías, por el Grupo Popular, véase: Diario de Sesiones. Congreso, $\mathrm{n}^{\circ} 120$, de 25 de noviembre, pp. 6282-6284.

23. Entre estos grupos, los populares citan expresamente a la Iglesia [Católica], de la que dicen ve la ley como «algo peligroso para su concepción del matrimonio y de la familia». Ibíd., p. 6284. Puede verse también TRÍAS SAGNIER, J.: «El contrato de unión civil y modificaciones legislativas que introduce», Actualidad Jurídica Aranzadi, 315 (1997), pp. 1-5. 
la interpretación constitucional que hace el PP es sesgada y va destinada a que no se pueda aceptar la equiparación con el matrimonio y la familia, pese a que existen sentencias y leyes ya efectivas en el Estado español que apoyándose en la Constitución, tienden a esta equiparación; las alusiones a interpretaciones trascendentes, con las que se intenta proteger el matrimonio y la familia tradicional; la subordinación de este tema al matrimonio en vez de considerar su propia especificidad ${ }^{24}$.

Para la señora Rahola i Martínez, con esta propuesta el Partido Popular pretende desvirtuar el debate de las parejas de hecho, y con él, «el derecho de toda persona a crear modelos de familia diferentes al tradicional, pero basados en el amor y el compromiso"; y deja muy lejos en la historia la reclamación de la regulación de las parejas de hecho. Coincidente en algunos extremos es la posición del Partido Democrático de la Nueva Izquierda, entiende que es un parche para no reconocer algo a lo que ha aludido el señor Trías, que es la libertad y la constitucionalidad de las diferentes opciones sexuales que pueda haber. Ya que «lejos de ser un derecho anticonstitucional, como lo ha querido plantear, es un derecho de pura constitucionalidad y libertad. Las personas tienen derecho a amarse, sean o no del mismo sexo, tienen derecho a ese compromiso ante la sociedad y tienen derecho a plantear que su unión tenga los efectos que ellos quieran darle y que la ley les permita». Iniciativa per Catalunya-Els Verds también se pronuncia en términos similares. "Entendemos que esto más allá del debate político, esto es una burla, es como una pesadilla para un colectivo que desde hace años viene solicitando una ley de parejas de hecho» ${ }^{25}$.

El señor Mardones Sevilla defiende, frente a la nueva, la proposición que presentada por su Grupo fue tomada en consideración. Y votarían en contra por ser «un planteamiento conceptual política y jurídicamente diferente». Lo que en su día se presentó supone dar derechos en un Estado democrático de Derecho a los efectos jurídicos de las parejas de hecho estables, no una unión civil que recuerda una fórmula de legislación mercantil. "A mí me parece una ofensa que, en el espíritu del tipo de parejas heterosexuales u homosexuales que nosotros planteábamos y que querían estar en el Estado de Derecho, se diga aquí que se trata de respetar la libertad de quienes quieren relacionarse más allá del Derecho ${ }^{26}$. Convergència i Uniò, socio del partido en el gobierno, mantiene una postura particular. Comienza afirmando que el Grupo Parlamentario Catalán desde el inicio en esta legislatura del planteamiento de la cuestión que nos ocupa, ha tenido claros tres aspectos fundamentales: la necesidad de regulación de esta materia; la regulación con consenso, ya que por las características propias del tema, al afectar directamente a la libertad y a la dignidad de las personas era absolutamente fundamental intentarlo, y así evitar que pudiera cambiarse en cada legislatura; y el contenido de la regulación específica. Por lo que se refiere

24. Véase: Diario de Sesiones. Congreso, n 120, de 25 de noviembre, p. 6285.

25. Ibíd., p. 6287.

26. Ibíd., pp. 6287-6288. 
al contenido específico de la regulación que debe tener esta materia, remiten a su propio proyecto ${ }^{27}$. La posición no es coincidente con la del Grupo Popular ni con la de Coalición Canaria. Con el PP porque el proyecto no efectúa un reconocimiento expreso de eso que ya está reconocido perfectamente en la realidad social: las parejas integradas por personas del mismo sexo, porque atribuye efectos idénticos a realidades sociales que son diferentes: como puede ser la pareja heterosexual, la pareja homosexual y otras unidades de convivencia, y además, por el coste económico.

Y, ni el Grupo parlamentario Federal de Izquierda Unida, ni el Grupo socialista, están de acuerdo con la proposición de contrato de unión civil. Para la señora Urán González, lo que se consigue es una regresión respecto a textos legislativos ya aprobados en ésta Cámara y una regulación que no contempla la protección a la familia y la protección a las unidades familiares que a tenor de nuestra Constitución deben ser atendidas por los poderes públicos ${ }^{28}$. Y por el PSOE, el señor Pedret i Grenzner pedirá la retirada de la proposición por suponer casi un fraude de Reglamento. Califican la proposición de «auténtico dislate jurídico, económico, social y político». Y en lo que nos parece más relevante, el grupo socialista argumenta que están introduciendo una disolución del concepto de familia, al confundir interesadamente matrimonio y familia, pese a la existencia de otras familias no basadas en el matrimonio; e intentar la existencia de una legislación en la que por una parte esté el matrimonio al que atribuyen carácter familiar, y por otra, mezclados en la misma ley, cosas que son familia, con situaciones que no tienen nada de familiares ${ }^{29}$.

Por último, para concluir este apartado y completar así el debate y el marco normativo, hay que decir que, paralelamente a lo que sucede en las Cortes Generales, los parlamentos de las comunidades autónomas debaten la regulación de las UDH y paulatinamente, aunque con diferente alcance y contenido -también en función de sus propias competencias tal como se establece en el texto constitucional-, van aprobando leyes sobre UDH. La primera de ellas fue la catalana, en la que se diferenció en cuanto a su regulación, entre UDH heterosexuales y homosexuales ${ }^{30}$.

27. En la sesión del Gobierno de la Generalitat de Catalunya, celebrada el 25 de noviembre de 1997 se toman entre otras las siguientes medidas: «A proposta de la Consellera de Justicia s'aprova l'avantproyecte de Llei sobre relacions de convivència diferents del matrimoni i s'autoriza l'esmentada consellera perquè el presenti al Parlament», véase: Butlletí Oficial del Parlament de Catalunya, n² 242, de 30 de desembre de 1997, pp. 18555-18562.

28. Véase: Diario de Sesiones. Congreso, n 120 , de 25 de noviembre, pp. 6290-6291.

29. Id., pp. 6291-6293.

30. Pueden consultarse, entre otros: AmUnÁTegui Rodríguez, C.: Uniones de Hecho. Una nueva visión después de la publicación de las Leyes sobre parejas de hecho, Valencia, Tirant lo Blanch, 2002; MEIL LANDWerlin, G.: Las uniones de hecho en España, Madrid, CIS, 2003; MESA MARrero, C.: Las uniones de hecho, Navarra, Aranzadi, 2006. 


\section{LOS COLECTIVOS HOMOSEXUALES: DEMANDAS Y PROPUESTAS}

Los colectivos homosexuales reaccionaron ante la proposición del PP. La Comisión de Derechos de la Coordinadora gay-lesbiana (GLV), redactó un manifiesto que el 25 de noviembre de 1997 entrega a los grupos parlamentarios, en contestación a la proposición del partido popular. Del manifiesto, encabezado por un título reivindicativo: Familias diversas, iguales derechos, entresacamos algunas cuestiones por su significación: «[...] En consecuencia creemos oportuno que se continúe discutiendo, enmendando y mejorando el Proyecto de Ley de Parejas de Hecho presentado por Coalición Canaria y admitido a trámite por el Congreso de los Diputados el pasado 27 de mayo. Y, sin perjuicio a que puedan regularse otras formas de relación o compañía, nos oponemos al Proyecto de Ley Orgánica de Uniones Civiles presentado por el Partido Popular que elimina la equiparación de las parejas de hecho al matrimonio tal como ya figura en las anteriores leyes referidas y que sería un retroceso en el reconocimiento e igualdad de derechos de las parejas de hecho respecto del matrimonio ${ }^{31}$.

31. El escrito nos ha sido facilitado por la GLV, y está firmado por el Colectivo de Lesbianas y Gays de Madrid (COGAM), el Col.lectiu Lambda de València, la Coordinadora Gai-Lesbiana. Su contenido íntegro es el siguiente:

«La situación de discriminación y desigualdad que sufren las parejas de hecho en nuestro país respecto de las parejas matrimoniales no puede continuar perdurando por más tiempo.

Problemas derivados de los derechos de sucesión, pensiones, seguridad social, residencia de pareja extranjera, etc. exigen respuesta inmediata. Especialmente se ven discriminadas las parejas de gays y de lesbianas afectadas por el VIH/SIDA cuyos problemas requieren una urgente y solidaria solución.

Ante esta situación las entidades, ONG's y personas firmantes desean manifestar ante la opinión pública, grupos parlamentarios del Congreso de los Diputados y Gobierno del Estado que:

Consideramos básicos para la ordenación de nuestra convivencia el respeto a los principios constitucionales de no discriminación e igualdad de todas las personas, libre desarrollo de la personalidad y protección de la familia.

Entendemos que el matrimonio no es la única forma de organizar la libre relación afectiva entre las personas. Asistimos en la actualidad al desarrollo de diversas formas de familia en nuestra sociedad. En este sentido las relaciones de pareja estables no matrimoniales no tienen por qué sufrir pérdida de derechos.

Ciudadanas y ciudadanos somos iguales en deberes y derechos, luego no debe conculcarse por más tiempo la igualdad de derechos por causa de la forma de relación amorosa libremente adoptada.

Nos felicitamos por los avances legislativos que ya en nuestro país han comenzado a equiparar las parejas de hecho al matrimonio como análoga relación de afectividad con independencia de la orientación sexual así reza la LAU, la Ley de Indemnizaciones a Víctimas de la Violencia y varios artículos del Código Penal, en su día promulgado con pleno consenso del arco parlamentario por lo que respecta a las parejas de hecho.

Así pues, atendiendo a esta fórmula de equiparación que coincide además con numerosas sentencias de nuestra jurisprudencia y con las recomendaciones del Parlamento Europeo de febrero de 1994, que igualan los derechos de las parejas homosexuales al matrimonio, instamos al poder legislativo a continuar por esta vía de equiparación de derechos.

En consecuencia creemos oportuno que se continúe discutiendo, enmendando y mejorando el Proyecto de Ley de Parejas de Hecho presentado por Coalición Canaria y admitido a trámite por el Congreso de los Diputados el pasado 27 de mayo. Y, sin perjuicio a que puedan regularse 
En enero de 1998 Miguel Ángel Sánchez Rodríguez presidente de la Fundación Triángulo por la igualdad social de gays y lesbianas, critica en un artículo las trabas puestas por el Partido Popular a la ley de parejas ${ }^{32}$. En su opinión el PP ante la puesta en marcha del trámite parlamentario de una ley que reconocía a las parejas homosexuales como unidades familiares, se vio obligado a presentar su propio texto. Texto en el que tienen cabida situaciones distintas a fin de no reconocer que las parejas de hecho son familia, opinión que fue expresada de manera clara por el señor Trías.

La prensa, atenta a este tema desde el principio, también recogió las diferentes posturas que se suscitaron con ocasión tanto de la presentación de la proposición del PP como de la toma en consideración ${ }^{33}$.

Ante la posibilidad de que se eternizara la tramitación parlamentaria, los colectivos homosexuales convocaron a una macro manifestación en Madrid para el 28 de marzo bajo el lema: «ley de parejas, ya» ${ }^{34}$.

Ahora bien, si importantes son las actuaciones realizadas ante determinadas propuestas, mayor trascendencia revisten las actuaciones generales. A este respecto hay que decir que, los colectivos homosexuales han mantenido, aunque con diferente intensidad, una actitud activa en demanda de lo que consideran sus reivindicaciones básicas ${ }^{35}$. Y en lo referente a la problemática de las UDH parece que la intención ha sido la de englobar las cuestiones controvertidas sin diferenciación entre uniones homosexuales y heterosexuales, quizá para que se admitieran mejor éstas últimas. De modo que podría afirmarse que han

otras formas de relación o compañía, nos oponemos al Proyecto de Ley Orgánica de Uniones Civiles presentado por el Partido Popular que elimina la equiparación de las parejas de hecho al matrimonio tal como ya figura en las anteriores leyes referidas y que sería un retroceso en el reconocimiento e igualdad de derechos de las parejas de hecho respecto del matrimonio».

32. Véase SÁnchez Rodríguez, M. A.: "La Ley de Parejas y las zancadillas del PP», Temas para el Debate, 38 (1998), pp. 44-47. Miguel Ángel Sánchez Rodríguez es presidente de la Federación estatal de gays y lesbianas y miembro del colectivo gay de Madrid.

33. Entre los titulares más significativos: «Los 'gay' contra la idea del PP de enmendar la ley de parejas de hecho", "El PP presenta oficialmente su propuesta de ley de uniones civiles. La fórmula popular evita hablar de parejas de hecho», «El PSOE llama 'filibustero' al PP en relación con las parejas de hecho", "La ley del PP que admite todo tipo de uniones civiles dispara las pensiones de viudedad", "El Congreso acepta tramitar la proposición de ley sobre uniones civiles del PP. El PSOE describe el proyecto como 'incitación al fraude fiscal'", El País, 3 de septiembre de 1997, 20 de septiembre de 1997, 24 de septiembre de 1997, 10 de noviembre de 1997, 26 de noviembre de 1997, respectivamente.

34. Véase: «El movimiento Gay decide en Valencia una manifestación por la ley de parejas de hecho", El País, 19 de enero de 1998. Se da noticia del acuerdo de las organizaciones españolas de gays y lesbianas reunidas en su quinto encuentro estatal, por el que se convoca la manifestación. La protesta se organiza para «reclamar la Ley de Parejas de hecho [...] actualmente parada en el parlamento», y manifestar que están «rotundamente en contra» de la proposición del Partido Popular.

35. La documentación y el material al que a continuación se hará referencia nos ha fue facilitado por el CRECUL y el COGAM, a los que agradezco su colaboración, y muy especialmente a $\mathrm{M}^{\mathrm{a}}$ Elena de León y Mili Hernández, así como a todas aquellas personas que con su participación han hecho factible mi acercamiento y comprensión de la problemática homosexual. Para documentación general resulta de interés consultar las páginas webs de los diferentes colectivos. 
colaborado de manera significativa a crear el clima de opinión sobre el que se elaboraron los primeros borradores y proyectos.

No se puede afirmar que existiera una unanimidad absoluta ni en los planteamientos iniciales, ni en las diferentes cuestiones que han ido surgiendo al hilo de, lo que podrían llamarse, las negociaciones con los partidos políticos. Las variables en un primer momento consistían en apoyar lo que se denominó: una 'ley de máximos' o una 'ley de mínimos'. La distinción era importante ya que implicaba que, o se pedía la eliminación de las trabas que impedían contraer matrimonio a los homosexuales, o se era favorable a admitir proyectos diferentes, menos ambiciosos, aunque no alcanzaran el techo reivindicativo. De la documentación consultada se deduce la opción por la segunda posibilidad, que, ello no obstante no supone renuncia a los planteamientos propios sino un primer paso en la lucha por la igualdad. Un escollo posterior, venía dado por el tema de la adopción y la problemática generada en torno a la misma.

A partir de aquí, considero necesario hacer un breve apunte de cómo y cuál ha sido la actividad realizada por los colectivos homosexuales, o lo que es lo mismo, las demandas y propuestas por ellos planteadas.

En 1990 se crea el Comité reivindicativo y cultural de lesbianas (CRECUL) de Alcorcón (Madrid) ${ }^{36}$, y se inscribe por Resolución de la Secretaría General Técnica del Ministerio del Interior el 23 de enero de 199137. Al tiempo también se constituye la Federación de Gays y lesbianas (FEGL), cuya acta viene sellada por el Ministerio del Interior y el Ministerio de Asuntos Sociales.

Los trabajos realizados por los diferentes colectivos suponen la elaboración de distintos proyectos para regular las parejas de hecho que ven la luz durante el año $93^{38}$. Así, por ejemplo, el 20 de septiembre la FEGL remite una carta circular en la que se informa que el 18 de septiembre se realizó la presentación de la propuesta para regular las parejas no casadas con la que se viene a cubrir el vacío legislativo existente ${ }^{39}$.

36. El acta fundacional está firmada en Madrid a 16 de noviembre de 1990.

37. Con el número Nacional 97.216.

38. Véase SÁnCHEZ Rodríguez, MA.: "La Ley de Parejas y las zancadillas del PP», op.cit., p. 44.

39. La carta circular, firmada por $\mathrm{M}^{a}$ Elena de León y Miguel Ángel Sánchez, secretaria y secretario general respectivamente, es del siguiente tenor: «El pasado sábado, 18 de septiembre, se realizó la presentación de la propuesta para regular las parejas no casadas elaborada por la federación estatal de Gays y Lesbianas y que está siendo presentada a los diversos grupos políticos y sociales para su discusión y posterior aprobación.

La propuesta cubre el vacío legislativo existente y la desprotección que en este momento tienen tanto las parejas de gays y lesbianas como las de heterosexuales no casados.

El texto no trata, por tanto, exclusivamente las relaciones de pareja entre personas del mismo sexo, sino que es global para todas las parejas, mencionando expresamente ambas posibilidades.

La FEGL, está enviando este proyecto a múltiples grupos sociales tanto de gays y lesbianas como otros movimientos sociales, iniciando de este modo un debate que concluirá con la aprobación de una ley que ha sido el eje básico de las demandas de gays y lesbianas desde la transición: el reconocimiento de las parejas de hecho y su regulación jurídica. Una realidad social que aún no ha sido recogida por el legislador. 
Uno de los primeros a los que he tenido acceso, contempla la regulación para las Parejas de Hecho, entendiendo por tales: «La unión estable entre dos personas, sean o no del mismo sexo, sin vínculo matrimonial previo subsistente, que comporte una comunidad de afecto y de bienes análoga a la del matrimonio» (art. 1) $)^{40}$.

Se apunta lo que se considera como fundamental o básico a la hora de realizar una regulación de las UDH: la definición o concepto, el modo de acreditar la relación, la equiparación al matrimonio en cuanto a determinados efectos

Esperamos que el proyecto os parezca interesante, en caso de que así sea y queráis apoyarlo, os rogamos nos lo hagáis saber lo más pronto posible, de forma que podamos analizar posibles campañas. Para cualquier información adicional poneos en contacto con la dirección que encabeza la carta».

40. El resto del proyecto era del siguiente tenor:

"Artículo segundo. Esta relación afectiva y de bienes análoga a la del matrimonio, producirá sus mismos efectos contractuales y jurídicos cuando: a) Los convivientes se inscriban en el Registro Municipal de la ciudad donde residan y que a tal efecto deberá ser aperturado por las Entidades Locales en virtud de la autonomía administrativa que la Constitución española les otorga, tras la presentación del documento de empadronamiento en un mismo domicilio particular, expedido por el propio ayuntamiento a efectos censales. B) Mediante acta notarial en la que los convivientes, en acto consentido y libre de su voluntad, ante el fedatario público, haga constar su situación de convivencia como pareja de hecho ante la imposibilidad, en el caso de parejas del mismo sexo, de contraer matrimonio bajo el ordenamiento jurídico español. C) Por cualquier otra prueba de las admitidas en Derecho y tras seis meses de convivencia demostrada en un mismo domicilio particular. D) En el caso de que en las mencionadas parejas de hecho, concurran hijos biológicos de los mismos ambos convivientes, las previas disposiciones les serán de aplicación con independencia de la duración de su convivencia.

Artículo tercero. El régimen económico al que quedará sometida la Pareja de Hecho, será el Régimen de Separación de Bienes.

Artículo cuarto. La Pareja de Hecho, fundada y formada por los convivientes, se considerará disuelta: a) Por muerte, Declaración de Fallecimiento o expedición del Certificado de Defunción, una vez cumplidos los plazos y efectos de la Ausencia. B) Por voluntad unilateral declarada de forma expresa por cualquiera de los convivientes, dejando sin efecto la comunidad afectiva y de bienes, análoga a la del matrimonio y obtenida previamente por cualquiera de los medios expuestos en el Artículo Segundo manifestada ante el Registro Municipal donde estuviera inscrita la relación, ante el Notario que expidió el Acta de Convivencia o cargando con prueba contraria a la presentada como cualquiera de las admitidas en Derecho.

Artículo quinto. Una vez disuelta la Pareja de Hecho, cesarán todos los efectos contractuales y jurídicos análogos a los del matrimonio. Las partes acordarán un régimen económico disolutorio en el que intervenga la autonomía de la voluntad y en el que, en caso de desacuerdo, dirima la figura de un juez de Familia aplicando la analogía respecto de las normas del Régimen económico Matrimonial y del Régimen de Separación de Bienes.

Artículo sexto. Los efectos jurídicos, análogos a los del matrimonio, comprenderán los relacionados con todo el derecho de familia y sucesiones: nacionalidad, filiación, patria potestad, tutela, curatela, adopción, herencias testadas y ab-intestato, derecho laboral, seguridad social y pensiones, derecho tributario, derechos arrendaticios, etc.; Instando a las Cortes Generales y al Gobierno del Estado español la exigencia de desarrollar, por mandato del artículo 9.2 de la Constitución Española, el contenido de la Recomendación del Parlamento Europeo sobre la Igualdad de Derechos de los Homosexuales y Lesbianas en la Unión Europea de febrero de 1994, removiendo todos los obstáculos formales y jurídicos que los Códigos y Leyes Especiales, Orgánicas u Ordinarias, presenten, de acuerdo también con los artículos 10.1 y 14 sobre Derechos y Libertades Fundamentales como valores superiores del ordenamiento jurídico español por el artículo 1.1 de la misma norma fundamental». 
jurídicos; la remoción de los obstáculos formales y jurídicos que impidan la igualdad. Hay que advertir que los borradores más apoyados fueron los que contenían propuestas de mínimos.

Borradores como éste fueron tomados en consideración en la elaboración del texto realizado por el Ministerio de Asuntos Sociales y presentado por la Ministra Cristina Alberdi a los medios de comunicación a finales del año $94^{41}$. Se dijo que, "el proyecto de ley sobre familias de hecho (sin vínculo matrimonial) no discriminará a los homosexuales ni lesbianas, ya que en esta futura normativa legal no se tiene en cuenta la condición sexual de los integrantes de estos núcleos familiares» ${ }^{42}$.

El CRECUL no sólo plantea sus reivindicaciones en el ámbito nacional. En enero de 1995 ejercen el derecho de petición ante el Parlamento Europeo a fin de que desaparezcan las discriminaciones para las relaciones entre personas del mismo sexo. El objetivo era conseguir que por el Parlamento se emitiera una directiva, no una recomendación. El documento estaba dirigido al Presidente de la Comisión de Peticiones del Parlamento Europeo ${ }^{43}$. La Comisión de Peticiones admitió la solicitud al considerar que las cuestiones planteadas tienen cabida en el ámbito de actividades de las Comunidades Europeas ${ }^{44}$.

41. En la Navidad de 1994 en una carta de felicitación de la Ministra de Asuntos Sociales a Ma Elena de León (CRECUL), se puede leer: «[...] a la vez que agradeceros el apoyo firme de todos vosotros para realizar las difíciles y gratificantes tareas de gobierno. [...] Sé que se han conseguido logros importantes, pero también sé que no podría haberlo hecho sin vuestra colaboración y apoyo".

42. Véase: El País, 15 de diciembre de 1994: «La ley de uniones de hecho no discrimina a los homosexuales, según Alberdi». Según la información que se contiene en la noticia, la Ministra indicó que esta ley igualará los derechos de las familias de hecho con las tradicionales, tanto en los aspectos administrativos, como laborales y civiles. El texto que estaba «bastante avanzado» no llegó a presentarse por el Gobierno dada la disolución anticipada de las Cortes.

43. Está fechado en Madrid a 27 de enero de 1995. "Ante la sensibilidad mostrada por el Parlamento europeo hacia la mejora legal y social de los homosexuales y lesbianas de la Europa actual, manifestada a través de recomendaciones como la emitida el pasado 8 de febrero de 1994 sobre la IGUALDAD DE LOS DERECHOS de los homosexuales y lesbianas en la Comunidad Europea (A3-0028/94), así como propuestas de resolución presentadas por los diputados: LOMAS, sobre los derechos civiles de los homosexuales y lesbianas (B3-1186/92), BETTINI y otros, sobre reconocimiento de las uniones civiles de parejas formadas por individuos del mismo sexo (B31079/92), conocedores, así mismo, del proyecto de directiva para luchar contra la discriminación por razones de orientación sexual en el ámbito laboral y otros ámbitos jurídicos, elaborado por la federación de homosexuales de Alemania (Schwunleuverband, SVD) de conformidad con el artículo 8D del Tratado de la Unión Europea de Maastricht, VENIMOS A EJERCER EL DERECHO DE PETICIÓN, en los siguientes términos:

Que por el Parlamento europeo se emita una directiva encaminada a la supresión de todas las disposiciones jurídicas existentes en los países de la comunidad Europea que discriminen las relaciones sexuales entre personas del mismo sexo así como la correspondiente adaptación de los derechos de los diferentes países hacia una equiparación de los derechos de gays y lesbianas a la del matrimonio".

44. En escrito de 22 de noviembre de 1995 se contestó a la solicitud en los siguientes términos: «Me complace comunicarle que la Comisión de Peticiones examinó su solicitud el 29 de mayo de 1995 y consideró que las cuestiones planteadas son admisibles en virtud del Tratado de la Unión Europea, es decir que su objeto incide en el ámbito de actividades de las Comunidades 
Las actividades del CRECUL siguen su andadura en lo concerniente a la regulación de las UDH por el parlamento español. De modo que continúan sus contactos con los grupos parlamentarios, presionan al PSOE una vez registrada su proposición y durante su tramitación. Y como Comité reivindicativo presentan su propio borrador al Grupo Parlamentario de Izquierda Unida en 1996, borrador que entienden se acerca más a los máximos que deberían contemplarse.

Del borrador -«Proposición de ley para la igualdad jurídica de las parejas de hecho con independencia de su orientación sexual»-, que fue tomado en consideración por IU para presentar su propuesta, vale la pena destacar que en la Exposición de Motivos se contempla como justificación los argumentos que utilizara la izquierda ${ }^{45}$.

Europeas. La Comisión consideró oportuno que las observaciones formuladas en la petición sean trasladadas a la Comisión de Libertades Públicas y de Asuntos interiores del Parlamento Europeo.

La Comisión de Peticiones me ha encargado informarle que sobre esta base se ha concluido el examen de su petición». Del tema se hizo eco la prensa, así por ejemplo en El Mundo, de 19 de abril de 1997, se puede leer el siguiente titular: «Los 'gays' apremian a la Eurocámara a aprobar sus derechos".

45. "La existencia real de las uniones de hecho independientemente de su orientación sexual en nuestro Estado Español es patente desde siempre, lo cual debe considerarse como una realidad cotidiana. Hay amplia jurisprudencia que lo demuestra y se han llegado a recoger y regular legislativamente algunos derechos, véase Ley 21/1987 de 11 de Noviembre que reconoce a las parejas unidas de forma permanente por relación de afectividad análoga a la conyugal, la posibilidad de adoptar hijos conjuntamente, véase la última Ley de Arrendamientos Urbanos, la Ley reguladora del derecho al Asilo y Ley Orgánica del Poder Judicial.

Diversos países de la CE han regulado ya diversos derechos de las uniones de hecho con independencia de su orientación sexual.

Nuestra Constitución Española en el Art. 14 de Capítulo II. Derechos y Libertades. Dice «Los españoles son iguales ante la ley, sin que pueda prevalecer discriminación alguna por razón de nacimiento, sexo, religión, opinión o cualquier otra condición o circunstancia personal o social». Entendemos, pues, tal condición o circunstancia personal o social aplicable a la orientación sexual de cada individuo. Así mismo, nuestra Constitución en su artículo 32. sección segunda. De los derechos y deberes de los ciudadanos. Dice: «El hombre y la mujer tienen derecho a contraer matrimonio con plena igualdad jurídica» de ninguna forma interpreta la unión matrimonial como un deber, si bien es así, las personas que no hayan hecho uso de este derecho y hayan decidido unirse en análoga relación de afectividad no han de ser excluidas de su derechos de pareja estable en plena igualdad con respecto a las uniones matrimoniales, e independientemente de la orientación sexual, en coherencia con el artículo 14 de nuestra Constitución. En definitiva el Artículo 39 de nuestra Constitución indican la obligación de los poderes públicos de asegurar la protección social, económica y jurídica de la familia.

Por otra parte, la Resolución del Parlamento Europeo de 8 de febrero de 1994 sobre la igualdad de derechos de los homosexuales y lesbianas en la CE, pide expresamente a los Estados Miembros, punto 7. Que se ponga fin al trato desigual de las personas de orientación homosexual en las disposiciones jurídicas y administrativas, así mismo pide expresamente a la Comisión de la Comunidad Europea. Punto 14. que la recomendación debería poner fin entre otros a la prohibición de contraer matrimonio o acceder a regímenes jurídicos equivalentes a las parejas de lesbianas o de homosexuales; la recomendación debería garantizar los plenos derechos y beneficios del matrimonio permitiendo la inscripción de la convivencia, y a toda restricción de los derechos de las lesbianas y de los homosexuales a ser padres, a adoptar o criar niños. 
Una vez tomada en consideración la proposición canaria, también los colectivos siguen estando presentes en el iter de la tramitación parlamentaria. Así, tenemos noticia de que fueron convocados por la Subcomisión que se crea en la Comisión de Justicia del Congreso para el estudio de la regulación de las situaciones y efectos jurídicos derivados de las uniones de hecho ${ }^{46}$, y también de la elaboración de enmiendas que presentan a los grupos parlamentarios.

El Colectivo de Gays y Lesbianas de Madrid (COGAM) elabora unas enmiendas parciales a la Proposición de ley sobre reconocimiento de efectos jurídicos a las parejas de hecho estables y modificación de determinados efectos aspectos del Código civil, estatuto de los Trabajadores, Ley General de la Seguridad Social, Medidas para la Reforma de la Función Pública, Clases Pasivas del Estado y de la Ley del Impuesto sobre Sucesiones y Donaciones, para consensuar por los grupos de gays y lesbianas, y que fueron presentadas al PSOE dentro del plazo de presentación de enmiendas a la proposición canaria ${ }^{47}$.

De entre las modificaciones alternativas que se proponen considero relevante entresacar y reproducir las siguientes:

Con todo ello se pretende con el presente proyecto de ley la equiparación jurídica de las personas que convivan en análoga relación de afectividad con independencia de su orientación sexual, considerándose unión de hecho a la unión libre, pública y notoria de dos personas independientemente de su orientación sexual, mayores de edad, sin vínculos de parentesco en primer y segundo grado de consanguinidad. Ninguno de los miembros de la unión de hecho podrá estar unido por un vinculo matrimonial en vigor, a otra persona, salvo en los supuestos en que la ruptura de dicho vinculo sea imposible por causas ajenas a las voluntades de las partes.

La unión de hecho podrá acreditarse a través de la inscripción en los registros específicos existentes en las Comunidades Autónomas o Ayuntamientos, a través del padrón municipal o mediante documento público. Cuando se extinga la unión de hecho ambos miembros o un solo miembro de la misma instará la cancelación de la inscripción en los registros correspondientes y/o anulación de los documentos».

Tiene fecha de 4 de noviembre de 1996. Por lo que respecta a las modificaciones legislativas que propone estas afectan al: Código Civil, Estatuto de los Trabajadores, Ley General de Seguridad Social y, Código Financiero y Tributario; y son substancialmente coincidentes con las presentadas en la proposición del Grupo Parlamentario Federal de Izquierda Unida-Iniciativa per Catalunya. Puede verse: Boletin Oficial de Las Cortes Generales. Congreso de los Diputados. VI Legislatura, Serie B, nº 88-1, de 10 de abril de 1997.

46. El Presidente del Congreso de los Diputados, en fecha 3 de junio de 1997 (con Registro de salida del día 4), convoca a Doña M $M^{a}$ Elena Criado de León (Presidenta del CRECUL) con la siguiente carta: "La Subcomisión para el estudio de la regulación de las situaciones y efectos jurídicos derivados de las uniones de hecho, con independencia del sexo de sus integrantes, y otras formas de convivencia distintas del matrimonio, ha acordado solicitar la comparecencia de diversas personas y representantes de organismos con reconocida experiencia o conocimientos sobre el tema, entre los que se encuentra usted.

A tal efecto, me complace convocarle para el día 10 de junio de 1997, a las 19.00 horas, a fin de que pueda proponer a la Subcomisión su opinión respecto a la problemática objeto de estudio». Parece lógico suponer que en términos similares han sido convocados otros colectivos. Otro tanto se desprende de la tramitación que realiza el Parlamento de Cataluña, ya que en los antecedentes del «Proyecte de llei sobre relacions de convivència diferents del matrimoni», el punto 6 se refiere a: «Persones, entitats i organismes consultats», véase: Butlletí Oficial del Parlament de Catalunya, cit., p. 18562.

47. Las enmiendas van firmadas por Pedro González Zerolo (COGAM) y Luisa Estévez Martínez. Abogada. 


\section{En el Capítulo I: Disposiciones Generales}

Artículo $1^{\circ}$.- «La presente ley será de aplicación a las parejas de hecho que cumplan con los requisitos señalados en la misma.

Son parejas de hecho las uniones de los mayores de edad o menores emancipados que, sin vínculo de parentesco en primer o segundo grado de consanguinidad y con independencia de su orientación sexual, estén unidas por una relación de afectividad pública y notoria, análoga a la de los cónyuges.

No podrán constituir pareja de hecho los que estén ligados por vínculo matrimonial».

Artículo $2^{\circ} \cdot 1^{\circ}$. ${ }^{*}$ Opción A: «La constitución de la pareja de hecho podrá acreditarse mediante su inscripción en los registros específicos existentes en la Comunidad autónoma o Ayuntamiento del lugar del domicilio».

*Opción B: «Las parejas de hecho deberán inscribirse en el Registro Civil del lugar del domicilio".

Artículo $2^{\circ} .2^{\circ}$.- "Cualquiera de los convivientes de la pareja de hecho podrá instar la cancelación de la inscripción de aquella. Dicha cancelación deberá ser notificada de forma fehaciente al otro conviviente» ${ }^{48}$.

Y por lo que respecta a las actividades en relación con la proposición del Grupo Popular, éstas ya han sido objeto de atención en páginas anteriores.

Para finalizar me gustaría dejar constancia de que siguiendo con los movimientos, actividades y reivindicaciones a que venimos haciendo referencia, la Asociación Internacional de Lesbianas y Gays (ILGA), cuyo secretario es Jordi Petit -en ese momento-, es ONG consultiva de los países miembros del Consejo de Europa ${ }^{49}$.

Hasta aquí he señalado las cuestiones a mi entender más relevantes que van coincidiendo en el tiempo con las proposiciones presentadas por los grupos parlamentarios de izquierda. Ahora bien, con ellas no se agotan las actuaciones

48. Además, se contemplan las siguientes: en el Capítulo II. Modificaciones al Código Civil, se deberá añadir un nuevo artículo por el que se modifican los artículos 807, 834, 837, 839, 840; se modifica el art. $22,2^{\circ}$ d) y e); se añade un nuevo art. que modifique el art. 175 párrafo cuarto, o se modifica la Disposición Adicional Tercera de la Ley 21/1987, de 11 de noviembre; se modifican los artículos 181, 182 y 183 del Código Civil en el sentido de ampliar las referencias que en dicho texto se hacen al cónyuge a los convivientes en las parejas de hecho; se modifica el art. 202 del Código Civil; se modifica el art. 234 párrafo primero del Código Civil; se modifica el art. 294 del Código Civil. En el Capítulo V. Legislación fiscal. Se propone una enmienda parcial a la proposición y, para que se modifique la Ley 18/91, de 6 de junio que regula el impuesto de la renta de las personas físicas, se modificará el art. 87. Además y por lo que se refiere a la Legislación de extranjería, se dice expresamente que «siendo Ley orgánica la ley que regula los derechos y libertades de los extranjeros en España, no puede pretenderse la modificación de la misma a través de esta Ley, que no tiene aquel rango. Sí podría pretenderse la modificación de algunos reglamentos o reales decretos que desarrollan aquella Ley».

49. Puede verse: El Mundo, 21 de enero de 1998, «La Asociación de Lesbianas y 'Gays', ONG consultiva del Consejo de Europa». El secretario general manifestó que se trata de "un avance histórico de los derechos de las lesbianas y gays en todo el mundo y una enorme contribución a la campaña que se está llevando a cabo coincidiendo con el 50 aniversario de la Declaración Universal de los Derechos Humanos: los derechos de lesbianas y gays son derechos humanos». 
de los colectivos homosexuales que han continuado en su línea reivindicativa hasta la aprobación de la Ley que nos ocupa.

\section{CONCLUSIONES: ¿FAMILIA/S?}

A día de hoy, resulta imposible realizar unas conclusiones generales, pero me gustaría establecer una serie de cuestiones a modo de conclusiones:

El debate en torno al acceso al matrimonio de personas del mismo sexo -el denominado comúnmente, matrimonio homosexual-, se conecta con la construcción tradicional del matrimonio y la familia. A este respecto considero imprescindible hacer notar su conexión con el matrimonio-la familia tradicional católica. Que en el caso español viene reforzada por la tradicional confesionalidad católica.

La sociedad española de las últimas décadas ha ido construyendo sus propios modelos familiares con lo que parece una tolerancia cada vez mayor de los $\operatorname{mismos}^{50}$, lo cual no lleva necesariamente consigo que exista una equivalencia entre los modelos sociales y los modelos jurídicos ${ }^{51}$.

La confesionalidad católica española ${ }^{52}$-a excepción de los dos períodos republicanos- hasta épocas relativamente recientes, ha tenido una repercusión clara en materia matrimonial. No sólo porque el matrimonio civil era una figura copiada a imagen y semejanza del canónico, ni porque el matrimonio canónico fuera preponderante, lo que conllevaba un sistema de matrimonio civil subsidiario, sino también porque junto al transvase de conceptos e instituciones se producía un transvase de valores de un ordenamiento a otro ${ }^{53}$. Jurídicamente, la situación cambia como he expuesto en páginas anteriores, con la aprobación del texto constitucional y la subsiguiente normativa de desarrollo. Se produce una cesura en los principios por los que se regían las relaciones Iglesia-Estado lo cual tiene su reflejo también en materia matrimonial.

50. Véase el número monográfico: «Familias y parejas: paradojas y nuevas opciones», Revista de Occidente, 199 (diciembre de 1997).

51. Sobre la temática social de la familia, ya a finales del siglo XX, véase CAMPO URBANO, S.: La evolución de la familia española en el siglo XX, Madrid, Alianza, 1982; Idem., Familias: sociología y política, Madrid, Editorial Complutense, 1995; ALBERDI, I. (dir.): Informe sobre la situación social de la familia en España, Madrid, Ministerio de Asuntos Sociales, 1995.

52. Puede verse MONTESINOS SÁNCHEZ, N.: La confesionalidad, pieza clave en la historia constitucional española y en el régimen franquista. Tesis Doctoral (inédita), Alicante, 1991.

53. Como ejemplificativo puede ser de utilidad: PÉREZ RUIZ, C.: La argumentación moral del Tribunal Supremo (1940-1975), Madrid, Tecnos, 1987. En particular y por cuanto se refiere a la «argumentación moral en relación con la familia», pp. 223-270. 
El 'ius connubii' se encuadra como un derecho constitucional ${ }^{54}$, no como un derecho fundamenta $1^{55}$, y el matrimonio como uno de los cauces posibles legalmente para el libre desarrollo de la personalidad; se invierte la relación entre 'ius connubii' e institución matrimonial siendo ésta quien está al servicio del desarrollo y realización de la primera, y no a la inversa, en razón del principio personalista ${ }^{56}$. Además, el ordenamiento prevé la libertad en cuanto a la forma de celebración sea esta civil o religiosa, con idénticos efectos civiles. Y por lo que se refiere a la familia, si el matrimonio ha sido básicamente la fuente generadora de la misma de modo que el modelo familiar se ha visto fuertemente caracterizado por la construcción de la institución matrimonial y en particular de la institución matrimonial canónica, hoy ya no existe acuerdo absoluto acerca del modelo familiar que se desprende del texto constitucional. De modo que el debate sobre el matrimonio homosexual y las UDH, habida cuenta que la Constitución, aún sin pronunciarse sobre $\operatorname{ellos}^{57}$, deja abierta la posibilidad de otros tipos de convivencia que también contribuyen a la realización de libre desarrollo de la personalidad, ha comprometido ambas instituciones.

Con todo, la Iglesia Católica no se ha mantenido al margen de la problemática actual. Su propia estructuración y concepción del matrimonio, con los requisitos de validez que lo caracterizan ha hecho que diferenciara claramente distintos supuestos, algunos de los cuales: como la estimación del matrimonio civil celebrado entre personas obligadas a la forma canónica, no tienen parangón en la legislación civil. Además, en su apreciación no sólo confluyen elementos distintos: jurídicos y pastorales ${ }^{58}$, sino que no entra a dirimir los efectos meramente civiles puesto que los considera de estricta competencia estatal ${ }^{59}$.

54. Encuadrado en la sección segunda del capítulo II, el artículo 32 establece: 1. «El hombre y la mujer tiene derecho a contraer matrimonio con plena igualdad jurídica». 2. "La Ley regulará las formas del matrimonio, la edad y capacidad para contraerlo, los derechos y deberes de los cónyuges, las causas de separación y disolución y sus efectos»; artículo que habrá que poner en relación con el 14 de la propia Constitución, el 16 de la Declaración Universal de Derechos Humanos, el 23 del Pacto de Derechos Civiles y Políticos, y el 44 del Código Civil.

55. En el ordenamiento canónico se habla de derecho natural, fundamental.

56. En este sentido, LlamaZARes FernándeZ, D.: El sistema matrimonial español. Matrimonio civil, matrimonio religioso y matrimonio de hecho, Madrid, Servicio de publicaciones de la Facultad de Derecho. Universidad Complutense, 1995, pp. 293-295.

57. En el artículo 27 del Anteproyecto se decía: «A partir de la edad núbil, el hombre y la mujer tienen derecho a contraer matrimonio y a crear, y mantener, en igualdad de condiciones, relaciones estables de familia». El Informe de la Ponencia de 17 de abril de 1978 reduciría texto y contenido: «A partir de la edad núbil, el hombre y la mujer, en plena igualdad de derechos y deberes, podrán contraer matrimonio para crear una relación estable de familia.

58. Ya que frente a la elaboración jurídica del modelo matrimonial canónico, no se puede hablar de un Derecho de Familia, ya que ésta encuentra dentro del ámbito eclesial su lugar adecuado dentro de la teología y la pastoral. Véase MARTínez BlANCO, A.: «La familia de hecho ante el Derecho Canónico y el derecho Eclesiástico", Anuario de Derecho Eclesiástico del Estado, XI (1995), pp. 189-224, en particular, p. 201; MONTESINOS SÁNCHEZ, N.: "Familia y Derecho...», op.cit., p. 363.

59. Así y con respecto al matrimonio canónico, en el canon 1059 se establece: «El matrimonio de los católicos, aunque sea católico uno sólo de los contrayentes, se rige no sólo por el derecho 
Frente a las posiciones adoptadas por algunos ordenamientos civiles tendentes a la equiparación de efectos con el matrimonio, ésta no se admite por la Iglesia, ya que no se trata tan sólo de que no se den los requisitos formales del matrimonio, sino y fundamentalmente, de que no hay un consentimiento que haga surgir la verdadera alianza matrimonial ${ }^{60}$. Y puesto que sólo cabe una unión matrimonial que sea heterosexual, se diferencia entre uniones o situaciones irregulares y uniones homosexuales.

Diferentes documentos se han pronunciado sobre ellas. La Exhortación Apostólica Familiaris Consortio entiende como situaciones irregulares «la unión sin algún vínculo institucional públicamente reconocido, ni civil ni religioso» ${ }^{61}$, e insiste en que «la familia está fundada sobre el matrimonio, esa unión íntima de vida, complemento entre un hombre y una mujer».

Por lo que se refiere a los homosexuales ${ }^{62}$, y en particular a las uniones homosexuales $^{63}$, merece la pena destacar que en diversos documentos de la Sagrada Congregación para la Doctrina de la Fe encontramos pronunciamientos sobre la consideración de la homosexualidad, la atención pastoral a estas situaciones, o las propuestas de leyes sobre no discriminación. "Según el orden moral objetivo de las cosas, las uniones homosexuales son actos que están privados de su necesaria y esencial ordenación [...] Los actos de la homosexualidad están desordenados por su intrínseca naturaleza y nunca pueden aprobarse por ninguna razón». Es más, "la inclinación misma debe ser considerada como objetivamente desordenada", [...] y ante el riesgo de que algunos grupos de homosexuales, incluso católicos afirmasen, en tono de protesta que "cualquier crítica o reserva en relación con las personas homosexuales, con su actividad y con su

divino, sino también por el canónico, sin perjuicio de la competencia de la potestad civil sobre los efectos meramente civiles del mismo matrimonio".

60. En este sentido, véase, VILADRIDCH, P.J.: "La familia 'soberana'», Ius Canonicum, 68 (1994), pp. 427-440.

61. Véase, Familiaris Consortio, n. 81.1. La situación de los católicos unidos con matrimonio civil, aunque englobada genéricamente en estas situaciones irregulares no sería del todo idéntica por la existencia de un vínculo y de una cierta estabilidad (n. 82).

62. Catecismo de la Iglesia. Constitución Apostólica «Fidei Depositum», 1992.

2357.- La homosexualidad designa las relaciones entre hombres o mujeres que experimentan una atracción sexual, exclusiva o predominante, hacia personas del mismo sexo. Reviste formas muy variadas a través de los siglos y las culturas. Su origen psíquico permanece en gran medida inexplicado. Apoyándose en la Sagrada Escritura que los presenta como depravaciones graves, la Tradición ha declarado siempre que «los actos homosexuales son intrínsecamente desordenados». Son contrarios a la ley natural. Cierran el acto sexual al don de la vida. No proceden de una verdadera complementariedad afectiva y sexual. No pueden recibir aprobación en ningún caso.

2358.- Un número apreciable de hombres y mujeres presentan tendencias homosexuales instintivas. No eligen su condición homosexual; ésta constituye para la mayoría de ellos una auténtica prueba. Deben ser acogidos con respeto, compasión y delicadeza. Se evitará respecto a ellos, todo signo de discriminación injusta. Estas personas están llamadas a realizar la voluntad de Dios en su vida, y, si son cristianas, a unir al sacrificio de la cruz del Señor las dificultades que pueden encontrar a causa de su condición.

63. Véase: AZNAR GIL, F.: "Las uniones homosexuales ante la legislación eclesiástica», Revista Española de Derecho Canónico, 52 (1995), pp. 157-190. 
estilo de vida, constituye simplemente una forma de injusta discriminación [...] La Iglesia no puede dejar de preocuparse de todo esto y por consiguiente mantiene firme su clara posición al respecto, que no puede ser modificada por la presión de la legislación civil o de la moda del momento [...]. La opinión según la cual la actividad homosexual sería equivalente o por lo menos igualmente aceptable, en cuanto expresión sexual del amor conyugal, tiene una incidencia directa sobre la concepción que la sociedad tiene acerca de la naturaleza y los derechos de la familia, poniéndolos seriamente en peligro» ${ }^{64}$.

Aun cuando hoy estas afirmaciones puedan producir una cierta perplejidad en algunos casos, no puede olvidarse que la homosexualidad desaparece del catálogo de enfermedades de la OMS a finales de los ochenta ${ }^{65}$, o, incluso que en España, siguen estando en los archivos policiales hasta los noventa.

Por todo, considero que la aprobación de la Ley supone una apuesta clara por parte del gobierno, e incluso puede tener una, al menos mínima, función pedagógica frente a un sector de población en algunos casos. Pero, aun cuando no se pueda negar el peso político de la opción asumida por el gobierno español, también es cierto que el debate acerca del matrimonio y la familia, no se cierra con la aprobación de la Ley. Sigue, cuando menos, con respecto a la adopción ${ }^{66}$, aun cuando diferentes informes mantienen que no supone ninguna situación de peligro para los menores, y ya existía la posibilidad en algunas leyes autonómicas, e individualmente por personas sin tomar en consideración su homo o heterosexualidad; también por lo que se refiere a la aplicación de la misma por los funcionarios competentes, y la posibilidad de alegar la objeción de concien$\mathrm{cia}^{67}$; y, por último, por la presentación del recurso de inconstitucionalidad por parte del Partido Popular ${ }^{68}$.

Si bien parece claro que hemos avanzado socialmente en la aceptación de modelos de convivencia diferentes del matrimonial tradicional, es de esperar que los pronunciamientos que se adopten en la resolución de situaciones de

64. Véase: Persona Humana, 29 de diciembre de 1975, n.8. En consonancia, la Familiaris Consortio dirá posteriormente que el matrimonio hunde sus raíces en el complemento natural que existe entre el hombre y la mujer y se alimenta mediante la voluntad personal de los esposos de compartir todo su proyecto de vida, lo que tienen y lo que son; por eso tal comunión es el fruto y signo de una exigencia fundamentalmente humana» (n. 19).

65. Importante también a este respecto la aportación de la Asociación de Psiquiatría de Nueva York.

66. Téngase en cuenta además que la idea del matrimonio como único lugar de la sexualidad lícita y para la procreación ya no es generalmente compartida. Bastaría hacer referencia a las nuevas técnicas de reproducción asistida.

67. Alegar objeción de conciencia en estos supuestos está totalmente en contra de todos los pronunciamientos de nuestro Tribunal Constitucional. Así lo ha entendido el Consejo General del Poder Judicial, por ejemplo, en el caso de la Jueza de Denia (Alicante), la primera que se negó a casar a una pareja homosexual. El Consejo General del Poder Judicial se ha pronunciado ya en dos ocasiones sobre la imposibilidad de alegar objeción de conciencia por los jueces encargados del Registro Civil. Sobre el particular pueden consultarse las webs de los colectivos homosexuales y del Consejo General del Poder Judicial, en las que encontramos tanto artículos de opinión como las posturas mantenidas.

68. Igualmente lo encontramos en las webs citadas y en la del Tribunal Constitucional. 
conflicto, estén en consonancia con las demandas sociales, ya que de lo contrario podríamos producir jurídicamente situaciones de involución, e incluso construir modelos familiares al margen, o contraviniendo, los preceptos constitucionales que a todas las personas amparan. 